\title{
Italian guidelines for the prevention and management of dental trauma in children
}

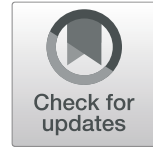

\author{
Maria Grazia Cagetti ${ }^{1}$, Piero Alessandro Marcoli ${ }^{2}$, Mario Berengo ${ }^{3}$, Piero Cascone ${ }^{4}$, Livio Cordone ${ }^{5}$, \\ Patrizia Defabianis ${ }^{6}$, Osvalda De Giglio $^{7}$, Nicola Esposito ${ }^{8}$, Antonio Federici ${ }^{9}$, Alberto Laino ${ }^{10}$, Alessandra Majorana ${ }^{11}$, \\ Michele Nardone ${ }^{9}$, Vilma Pinchi ${ }^{12}$, Silvia Pizzi ${ }^{13^{*}} \mathbb{D}$, Antonella Polimeni ${ }^{14}$, Maria Grazia Privitera ${ }^{15}$, \\ Valentina Talarico ${ }^{16}$ and Stefania Zampogna ${ }^{16}$
}

\begin{abstract}
Dental trauma is a frequent occurrence in children and adolescent and a correct diagnosis and treatment are essential for a favourable long-term prognosis. The present Guidelines aim to formulate evidence-based recommendations to assist dentists, paediatricians, surgeons, teachers, school and sport staff, parents in the prevention and first aid of dental trauma in children and to provide a careful assessment of the medico-legal implications, reviewing the first draft of the guidelines published in 2012. A multidisciplinary panel on the behalf of the Italian Ministry of Health and in collaboration with the WHO Collaborating Centre for Epidemiology and Community Dentistry of Milan, developed this document. The following four queries were postulated: 1) Which kind of precautions the health personnel, parents, sports and educational personnel must activate in order to prevent the dental trauma damage? 2) How an orofacial trauma in paediatric patients should be managed either in the Emergency Care Unit and/or in private dental office? 3) What criteria should be adopted by a dentist private practitioner to fill in a certificate in cases of dental and/or tempomandibular joint trauma occurring in children and adolescents? 4) What are the elements that should lead clinicians to suspect a non-accidental dental trauma? A systematic review and analysis of the scientific literature published in English, Italian and French from 2007 to 2017 regarding dental trauma in children and adolescents aged 0-18 years was performed, and about 100 papers were analysed and included. The following four domains were analysed and discussed: Dental Trauma Prevention Strategies and Health Education, First aid in orofacial and dental trauma, Certificate of the dental trauma, Oral and dental signs of child abuse and neglect. Twenty-eight recommendations were draw up and codified by the panel according to the Methodological handbook, produced by the Istituto Superiore di Sanità, in order to guide physicians in the prevention and first aid of dental trauma in children and adolescents. In addition, a careful assessment of the medico-legal implications is reported in this document.
\end{abstract}

Keywords: Children, Dental trauma, First aid, Evidence-based, Guideline

\section{Premise}

This document contains an update to the "National guidelines for the prevention and clinical management of dental trauma in children" published by the Ministry of Health in November 2012. An updated version of the guidelines was necessary due to the changing of the scientific evidence and the publication of research into the increasingly modalities by which dental and/or facial trauma is occurring in children, especially after animal bites. Traumas to

\footnotetext{
* Correspondence: s.pizzi@unipr.it

${ }^{13}$ Department of Medicine and Surgery, University of Parma, Via Gramsci 14 43126 Parma, Italy

Full list of author information is available at the end of the article
}

the lower facial third that involve the temporomandibular joint (TMJ) have also been included in this document.

A lack of knowledge regarding such injuries and the consequent failure to provide adequate treatment may lead to functional deficits and aesthetic defects, especially in growing patients. As a result, articles published in the literature of the last five years on the prevention, first aid and certification of dental trauma in children have been considered.

In recent years, the prevalence of traumatic events involving the orofacial district, including the dental arcades, has increased, which has undoubtedly created a burden for public health [1]. This is due to an increasingly dynamic daily life, the increased involvement of 
growing individuals in play activities and competitive and non-competitive sports, the increasing use of motorized vehicles by adolescents, and the widespread habit of keeping pets, especially dogs [2].

School, the home, sports facilities and the road are where traumatic events occur with the greatest frequency. However, they are also places where it is possible to give information and put in place prevention measures. Information campaigns, through schools, sports clubs, television, newspapers, pamphlets and posters, and, above all, the internet are useful strategies for raising awareness of the prevention and first aid of dental and orofacial trauma in pre-school and schoolchildren $[3,4]$.

It is also important to consider child abuse, which often involves the orofacial district; Oral and dental trauma may lead to "sentinel" event that put the dentist in the position of responding reporter [5, 6]. Likewise, special attention should be paid to self-inflicted injuries [7].

Patients who have suffered dental injury often arrive at Accident and Emergency, requiring comprehensive multidisciplinary treatment (dental, maxillofacial, paediatric, medico-legal, sports medicine, emergency medicine and preventive medicine), necessary to obtain optimal functional and aesthetic recovery. For instance, the management of trauma involving the teeth and the facial district may include the treatment of the lacerated mucosa, the reduction of maxillary fractures (possibly involving the TMJ), the immediate restoration of traumatised teeth, reattachment of fractured coronal fragments, and reimplantation of avulsed teeth, where possible. Furthermore, physicians must tailor the approach taking into account the psychological distress experienced by the patient, who is often traumatised due to the anxiety and fear provoked by the event.

Trauma diagnosis and treatment have to carry out according to specific protocols, governing a care pathway that initially involves the accurate collection of the medical history and the circumstances of the traumatic event, and continues with an initial phase of objective clinical and radiological testing, a second phase involving specific therapeutic management, and a third monitoring over time the patient.

Most of the scientific literature available today emphasises that, frequently, neither parents or caregivers nor school, sports or even healthcare personnel have sufficient knowledge of the correct procedures to be applied when a dental trauma occurs. In fact, some studies indicate that only $4 \%$ of physicians provide appropriate first aid treatment procedures $[1,8]$.

The prognosis of certain injuries is dependent on early and correct management. Often, the first healthcare professional to manage the dental trauma is the emergency room doctor, hospital physician or paediatrician. The role of the paediatrician is particularly important, especially in terms of guiding the proper treatment pathway, as they are generally the clinicians to whom the parents turn whenever a healthcare issue arises with their child.

\section{Purpose}

The purpose of this document is to provide evidencebased recommendations and indications on the prevention and first aid of dental trauma in children, and a careful assessment of the medicolegal implications. (Fig. $1)$.

\section{Fields of application}

WHERE: The recommendations can be applied in the environments where a growing individual is exposed to in their daily life, and in all public and private health facilities where clinicians treat young patients who have experienced traumatic events involving the maxillofacial region.

WHO: The recommendations are aimed at GPs, paediatricians, maxillofacial surgeons, trauma surgeons, emergency room physicians, sports medicine practitioners, medico-legal specialists, dentists, dental hygienists, nursing staff, school staff, sports centre workers and parents or carers.

\section{Authors}

This document was drawn up by a multidisciplinary panel set up for the purpose at the behest of the "Technical Group for Dentistry" (Gruppo tecnico sull'odontoiatria, GTO), which is part of the Italian Ministry of Health General Secretariat.

\section{Panel}

Maria Grazia CAGETTI - University of Milan coordinator.

Piero Alessandro MARCOLI - Italian Dental Traumatology Society (Società Italiana di Traumatologia Dentale, SITD) - coordinator.

Mario BERENGO - University of Padua.

Piero CASCONE "Sapienza” University, Rome.

Livio CORDONE - "ASST- Spedali Civili" local health authority, Brescia.

Patrizia DEFABIANIS - University of Turin.

Osvalda DE GIGLIO - "Aldo Moro" University, Bari.

Nicola ESPOSITO - Italian National Association of Dentists (Associazione Nazionale Dentisti Italiani, ANDI). Antonio FEDERICI - Ministry of Health. Alberto LAINO - "Federico II" University, Naples. Alessandra MAJORANA - University of Brescia. Michele NARDONE - Italian Ministry of Health. Vilma PINCHI - University of Florence.

Silvia PIZZI - University of Parma.

Antonella POLIMENI - "Sapienza" University, Rome. Maria Grazia PRIVITERA - Italian Ministry of Health. 


\section{Dental Trauma Guidelines}

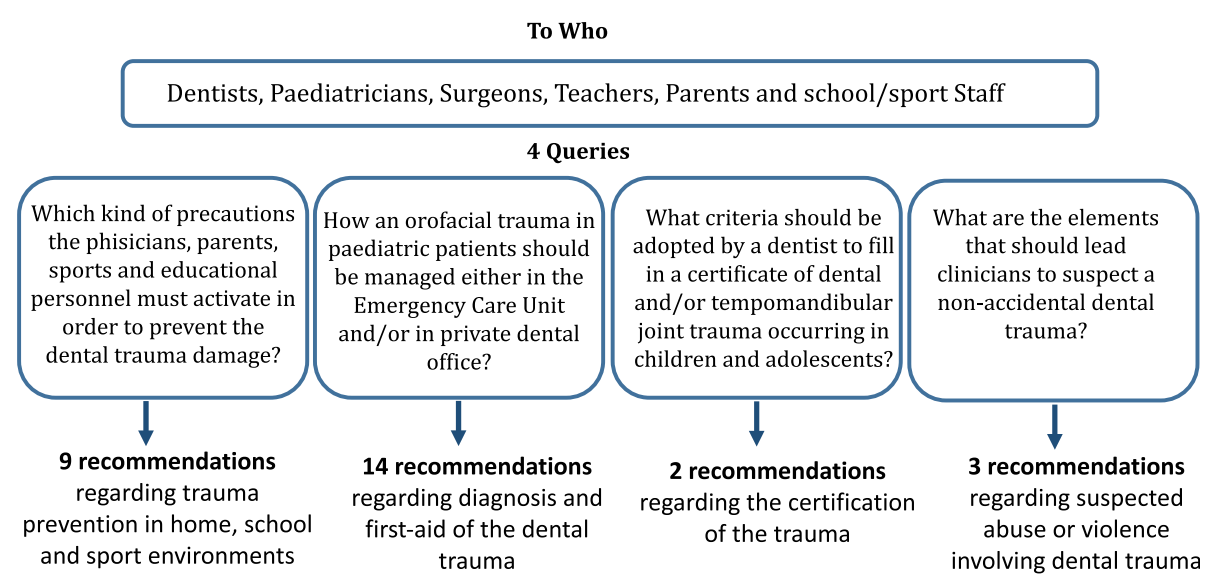

Fig. 1 Flowcharts of Guidelines development

Valentina TALARICO - "Pugliese Ciaccio" Hospital, Catanzaro.

Stefania ZAMPOGNA - Italian Society of Emergency Paediatricians (Società Italiana di Medicina di Emergenza ed Urgenza Pediatrica, SIMEUP).

This document was drawn up according to the guidelines provided by the Italian National Guideline Programme (Programma Nazionale per le Linee Guida, $P N L G$ ) [9] and underwent a process of consultation with experts from the Milan WHO Collaboration Centre for Epidemiology and Community Dentistry of Milan.

\section{Identification of objectives}

The following objectives were identified: 1) Dental Trauma Prevention Strategies and Health Education, 2) First aid in orofacial and dental trauma, 3) Certificate of the dental trauma, 4) Oral and dental signs of child abuse and neglect.

For each of the above objectives, a series of keywords was identified and these were used alone and/or in combination.

\section{Literature search}

A literature search was performed using the following electronic databases: The Cochrane Library, PubMed, Embase and Google Scholar.

In the first draft of the guidelines, papers published in English, Italian and French from 2007 to 2012 were included. This revised version relies on the same search criteria, extending the literature search to 2017.

Search limits: Only papers target on growing individuals (0-18 years of age) were considered for these guidelines.

\section{Scientific validity assessment}

Full-text articles were screened using a dedicated form. The panel was divided into subgroups, each of which independently screened the articles. Any disagreements were resolved by group discussion.

\section{Levels of evidence}

Following the scientific validity assessment, scientific evidence level tables were created, using Table 1 as a guide. This table shows the scores of the scientific evidence and describe its impact and clinical applicability, etc.

\section{Grading the recommendations}

The recommendations have been codified according to Table 2 [9].

\section{Peer-review}

A list of experts in each field developed by the present guidelines was drawn up by the panel and a draft of the document was sent to all of them, asking to critically review the document and to report any error or omission. All feedbacks were discussed and amended by the panel.

\section{Conflict of interest}

All members of the panel declare no interests conflicting with the purpose of this document.

\section{Dental trauma prevention strategies and health education}

Query: Which kind of precautions the health personnel, parents, sports and educational personnel must activate in order to prevent the dental trauma damage?

Keywords (MeSH term): traumatic dental injuries, public health, dental trauma, preventive strategies, mouthguards, helmet, schoolchildren, animal bite injuries, oral health promotion, oral health education, sports

Key words have been searched individually and in association each other 
Table 1 LEVELS OF SCIENTIFIC EVIDENCE

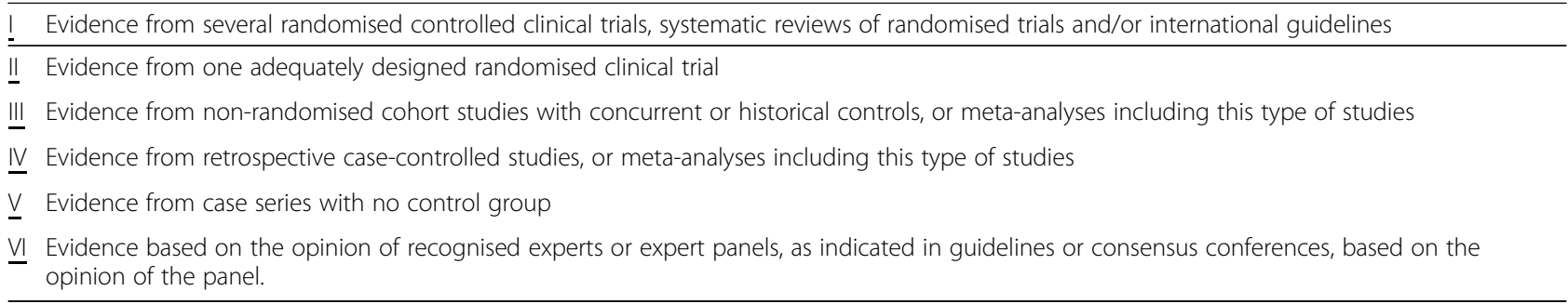

Inclusion criteria: only papers answering the question above were considered. All studies based on primary and secondary prevention in children in a domesticSport and road safety context were considered for a total of 130 papers. Fifteen papers were considered relevant and added to those selected for the previous version of the guidelinesGiving a total of 30 papers included

\section{Introduction}

Epidemiological studies show that overall, the incidence/ year of dental trauma stands at $4.5 \%$ : approximately a third of children and toddlers and a quarter of adolescents and adults [10].

The prevalence of dental trauma varies from 6.1 to $62.1 \%$ in pre-school children and from 5.3 to $21 \%$ in schoolchildren [11].

Traumatic events responsible for dental trauma can be found at home (stairs, wet floors, sharp corners) [2, 12, 13], at school [14] in sports setting (collisions, elbowing and falls) [15] and during free-time activities (bicycle rides, walking in woods and on the beach, use of roller skates, skateboarding and rollerblading, etc).

Specific traumatic events to the maxillofacial region can occur in public places (slippery surfaces, road works badlymaintained roads, and as a result of animal bites, etc).

\section{Prevention}

Observational studies have suggested that dental trauma can cause pain, functional impairment and aesthetic problem, with physical, emotional and social consequences for children and their families. This indicates the need for primary, secondary and tertiary prevention programmes in children and young adults [4].
The implementation of suitable primary measures of prevention with the aim of protecting healthy subjects depends on correct information being managed between dentists, orthodontists, dental hygienists, parents and carers, school and sports teachers working closely with paediatricians.

Secondary prevention measures must, however, be implemented when damage has occurred and are designed to limit the harmful consequences by means of a careful clinical evaluation and a correct treatment of the dental trauma [16].

Finally, tertiary prevention, strictly related to orthodontic treatment, has the aim of reducing complications and restoring chewing, aesthetic and phonetic functions.

\section{Primary prevention at home}

Babies, children and elderly people are the categories of people most at risk from domestic accidents.

For individuals within 14 years of age, the living room (area of the house dedicated to free time and games) is the most at-risk environment $(74.6 \%$ of domestic accidents) [17].

In early childhood, starting to walk, with or without a walker is the most frequent moment when dental trauma can occur as a result of the greater possibility of falling and hitting furniture [18].

Young and obese subjects also show a greater tendency to fall [19]; although the data currently available are not sufficient to establish a causal relationship between dental trauma, physical activity and nutrition [20].

In individuals showing an increased overjet (the distance between upper and lower incisors in the anteriorposterior direction) as occurs in subjects who habitually suck their thumbs or a dummy, dental trauma is more

Table 2 RECOMMENDATION STRENGTH

\begin{tabular}{ll}
\hline A & The procedure is strongly recommended based on good-quality scientific evidence (not necessarily type I or II) \\
\hline B & $\begin{array}{l}\text { There are doubts about the procedure or intervention should always be recommended, but it should, nonetheless, be taken into careful } \\
\text { consideration }\end{array}$ \\
C & There is substantial uncertainty regarding whether or not to recommend the procedure or the intervention \\
D & The procedure is not recommended \\
T & The procedure is strongly not recommended \\
\hline
\end{tabular}


common in the case of "face first" falls [21-23]. It is therefore important to have specialist orthodontic examinations to identify and correct early possible dental protrusions [24].

In all these subjects and particularly in lively individuals the use of mouthguards would be appropriate [12].

Oral trauma in infants can also be caused by animal bites (mainly cats and dogs), which, in addition to the physical and psychological damage, can cause infections [25]. The detection and removal of teeth or fragments of teeth is crucial in reducing significantly the risk of infection $[26,27]$.

In particular, prevention strategies against dog bites should include careful supervision of the interaction between infants and dogs, education relating to the responsibility of dog owners and observance of the rules relating to the control of animals.

It is also necessary to increase knowledge in the community of the rabies virus and the necessity to vaccinate animals against it [25].

Recommendation 1

It is important to adopt measures to discourage nonnutritional sucking by two years of age in order to completely arrest the habit in the following year, since it is a risk factor for the overjet increase.

Recommendation strength: A.

Level of evidence: I.

Recommendation 2

In the case of increased overjet, parents should be informed of the risk of dental trauma caused by face falls and suggest an orthodontic evaluation.

Recommendation strength: A.

Level of evidence: IV.

\section{Primary prevention at school}

Given the frequency of dental trauma in a school environment it would be useful for educational institutions to organise training courses for teachers, school employees and students with the aim to identify and reduce risks of dental trauma in children [28, 29].

The choice of the teaching method should take into account technological developments, of which the audio-visual supports have been shown to be most effective in communicating educational messages [30].

The most common traumas are a consequence of the habit of chewing pens and keeping stationery items in the mouth, fights [19], the playing of games that use blunt objects and falls during sports and recreational activities.

In all schools a first aid area should be present together with conditions to facilitate immediate intervention in the case of dental trauma.

Recommendation 1

It is recommended that training is given to teachers and non-teaching staff regarding the risk of dental trauma. These training courses should use videos, brochures and /or manuals. Posters and leaflets explaining risks should be put on walls of gyms and swimming pools.

Recommendation strength: A.

Level of evidence: VI.

Recommendation 2

It is recommended to inform and teach children regarding the risk of dangerous behaviour and its consequences.

Recommendation strength: A.

Level of evidence: VI.

\section{Primary prevention in sport ENVIROMENT}

Contact sport such as basketball, volleyball, football rugby and horse-riding but also non-contact sports such as swimming (wet surfaces surrounding the swimming pool) or artistic gymnastics and other sports activities such as cycling, using skateboards, roller skates or rollerblades and skiing represent some of the activities with an elevated risk of dental trauma in young people mainly as a result of falls or collisions with other participants $[31,32]$.

In these cases, both dentists and sports centre staff might suggest the use of helmets, mouthguards and/or facemasks suitable for the sport being practised, informing players of the risk of dental and facial damages and of the benefits of these safety measures [16, 33-35].

\section{Secondary prevention}

In the case of dental trauma the patient should be kept calm, any blood should be cleaned away and the nature of the damage caused should be evaluated carefully (type of teeth involved, dental fractures, mobility or partial extrusion of teeth, possibility of salvaging any tooth fragments or the entire tooth) and the type of first aid required (need for avulsion, replacement, reattaching the fragment/s, protection of the tooth pulp and/or the exposed tooth).

An avulsed tooth has a good probability of being reinserted if it has been kept in liquid solutions (physiological solution, milk or saliva). The prompt reinsertion is the procedure that has the highest percentage of success [10]. In addition, there is a good possibility of healing if the reinsertion, temporary splinting to other teeth (for 2 to 4 weeks) and further check-ups are carried out correctly $[12,36]$.

In all cases, a follow-up protocol is necessary in order to avoid complications arising.

If the event has occurred in a very early age, this represents a valid reason for a dental examination and a series of follow-up appointments during the following year, with the aim of reassuring the child of completely recovering the aesthetic of the smile.

Recommendation 1 
It is recommended to include sterile saline solution vials in first-aid kits.

Recommendation strength: A.

Level of evidence: III.

Recommendation 2

In cases of fracture of the crown of the tooth

1. it is recommended to retrieve the broken fragment.

2. it is recommended to go immediately to an Emergency Department with a dental service, or to a private dentist. When the tooth that has been avulsed is permanent, the reinsertion is recommended. If the avulsed tooth is a primary tooth, the reinsertion is not recommended.

Recommendation strength: A.

Level of evidence: I.

\section{First aid in orofacial and dental trauma}

Query: How an orofacial trauma in paediatric patients should be managed either in the Emergency Care Unit and/or in private dental office?

Keywords (MeSH term): traumatic dental injuries, dental trauma, paediatric facial trauma, TMJ fractures, children, adolescents, first-aid trauma, emergency

Key words have been searched individually and in association each other

Inclusion criteria: only papers answering the question above were considered. A total of 53 papers were foundAnd 22 were selected. Finally 39 papers were includedSince some of the references of the previous version of the guidelines were eliminated and/or substituted by the new ones.

\section{Introduction}

The efficacy of the management of oral-facial injuries in paediatric dentistry depends on a prompt and accurate diagnosis, followed by an appropriate treatment to improve the prognosis. In case of crown fracture or avulsion, the prognosis depends mainly on a quick and appropriate treatment to improve short and long-term outcome [37]. Signs and symptoms referred by patients must always be carefully evaluated to exclude systemic and/or local (orofacial region) complications. For this reason, it is necessary to manage all the most appropriate procedures to face the trauma since the first aid approach $[37,38]$.

Many papers concerning orofacial trauma in paediatric dentistry have been recently published [39, 40]; however, published papers do not fully address all the different clinical problems of dental traumatology, limiting to dealing with single aspects [41-44]. As a result, a useful and practice guidelines for clinicians (paediatricians, Emergency Care Unit staff or dentists) who face orofacial trauma in an emergency setting is needed [45].

Recommendation 1
Fragment/s of tooth/teeth and avulsed tooth/teeth should be put in a proper storage medium (milk, saline solution, saliva) before the replantation as recommended by 2011 AAPD and 2012 IADT Guidelines [36, 46-48].

Recommendation strength: A.

Level of evidence: I.

Initial evaluation at the emergency care unit

The first classification of a traumatic event and its priority code are given during the first evaluation of the trauma at the Emergency Care Unit $[49,50]$.

\subsection{Trauma History}

All information concerning the traumatic event must be collected. This includes:

- the place where the injury occurred (school, home, gym, road, etc.)

- the cause of the trauma (accidental fall, car accident, aggression, etc.)

- the dynamics of the traumatic event.

- the time and interval period existing between the event and the first aid.

- -signs and symptoms referred by the patient.

- recovery of avulsed tooth/teeth or tooth/teeth fragments and the medium used for the storage.

Recommendation 2

It is recommended to perform a scrupulous medical history targeting the following: the dynamics, place and modality of the traumatic event; the symptoms referred at the moment of the trauma, such as pain, loss of consciousness, confusional state, amnesia, headache, nausea/vomit, alterations of the sight, convulsive crisis, speech difficulties, bleeding and otorrhea; if tetanus vaccine is up to date.

Recommendation strength: A.

Level of evidence: IV.

Recommendation 3

The remote pathologic anamnesis, personal and familiar, must be precise, punctual and mainly targeting the hematologic diseases (clotting blood disorders), and/or pathologies which may influence treatment options (such as congenital heart diseases requiring antibiotic prophylaxis for bacterial endocarditis) or allergies.

Recommendation strength: A.

Level of evidence: III.

\section{Clinical examination of the patient}

In children the general physical examination, even in case of dental trauma, is very important since, in young patients, symptoms are not well described and systemic signs might be not clearly expressed [51]. 
Paediatricians and paediatric dentists must focus their attention on signs resulting from cervical and/or cranial trauma, such as bruises in the mastoid region, central or peripheral neurological problems, etc. [52-56]. In addition, injuries that may lead the clinician to suspect a child abuse (such as bruises which do not correspond to bone prominences, lesions due to recognizable objects, bites, burnings, injuries of different timing etc) must always be carefully considered [25].

Examination should also include the evaluation of jaw movements: mandibular range of motion (i.e. maximum unassisted opening, maximum assisted opening, maximum lateral excursion, maximum protrusive excursion) and opening pattern on the frontal plane (i.e. symmetrical vs asymmetrical) must be considered carefully. A functional examination should also include the evaluation of occlusion: the presence of occlusal alterations such as posterior pre-contacts, open bites, etc. must be recorded as they may be the result of temporo-mandibular joint (TMJ) involvement [57-59]. Underestimated TMJ fractures may result in abnormal facial growth, asymmetries and/or mandibular micrognathism [60, 61].

Teeth's position must be always examined in order to show up injuries with or without pulp exposure, displacement and/or tooth mobility.

Extra-oral examination must always consider:

- clinical signs which may imply cranial or cervical trauma;

- -lesions non-corresponding to bone prominences such as bruises, lesions due to recognizable objects, bites, burnings, injuries of different timing etc.

- presence of facial asymmetries;

- pain assessment (particularly during mandibular movements);

- evaluation of jaw movements, as reduced/deviated mouth opening may be the result of TMJ fractures, effusion and/or bleeding in the joint space.

- presence of bruises, lacerations/abrasions of perioral soft tissues.

- The intraoral examination [62-68] must always consider:

- teeth fractures (with or without pulp involvement), teeth dislocations, mobility or avulsion.

- soft tissue conditions, with special attention to oral mucosa, gingiva or tongue injuries;

- -careful assessment of post-traumatic occlusal alterations such as open bite and posterior pre-contacts.

Recommendation 4

In addition to the examination of the orofacial area

- a general assessment of patient's condition must always be considered;
- the presence of cranio-cervical injuries must be recorded;

- oral mucosae lesions and extra oral injuries pathognomonic for child abuse must always be recorded;

- the assessment of the mandibular dynamics is recommended.

Recommendation strength: A.

Level of evidence: III.

\section{Radiological diagnosis}

In case of suspected bone fractures, face radiograms such as panoramic X-ray (OPG), lateral (LL-TRX) and posteroanterior cephalograms (AP-TRX) and reverse Towne's views are very useful. The latter does not require a lot of child's cooperation and it is recommended in very young patients because of the low quantity of radiation delivered. Other methods of advanced imaging may be needed [69-71].

\section{Recommendation 5}

The radiological investigation of the facial district is necessary in order to exclude or confirm the presence of bone fractures. It is highly recommended in the case of direct or indirect facial traumas involving the orofacial region or the mandible. Other imaging investigations might be needed in case of multiple traumatic lesions and/or suspected child abuse.

Recommendation strength: A.

Level of evidence: III.

\section{Therapy}

Facial trauma requires a multidisciplinary approach: mid-face and mandibular fractures treatment is the responsibility of the maxillofacial surgeon, while dental and oral soft tissues lesions are the responsibility of the dentist. In case of trauma involving children and adolescents, only parents and/or caregivers can give consent to dental treatments [72, 73]. If needed, urgent diagnostic and therapeutic procedures (such as sutures of a wound, reduction of displaced teeth, tooth replantation, treatment of the exposed dental pulp, etc..) must be, however, done in order to prevent worse outcomes. Postponed treatments always need parents or caregivers consent.

Recommendation 6

In case of facial trauma, a specialist consultation is highly recommended to evaluate if the treatment of the traumatic lesions can be delayed or not (as in the case of tooth avulsion, pulp exposure etc.).

Recommendation strength: A.

Level of evidence: IV.

First dental assessment

The first assessment of a dental trauma in a child must provide a classification of the type of trauma in order to set up proper diagnostic and therapeutic procedures. 


\section{History}

A) If the patient has already been examined at the Emergency Care Unit

The dentist must evaluate the clinical and radiographic examination reports given by the Urgent Care Unit

B) If the patient has not been examined at the Emergency Care Unit

The first dental assessment includes the self-report history of the traumatic event and the clinical examination of the patient.

History of the traumatic event All the information concerning the traumatic event must be recorded, with special attention to:

- where the traumatic event occurred (school, home, gym, road, etc.);

- cause of the trauma (accidental fall, car accident, aggression, etc.);

- self-reporting of the traumatic event;

- timing of the trauma and time interval between the traumatic event and first aid;

- signs and symptoms reported by the patient;

- the presence of dental fragments for possible reattachment and/or presence of avulsed tooth/teeth suitable for immediate replantation (if stored in a proper medium) must always be carefully evaluated.

\section{Recommendation 7}

Complete medical and dental history must be recorded (see Recommendation n. 1).

Recommendation 8

If the patient showed systemic symptoms when the trauma occurs or during the dental examination, he/she should be immediately sent to the Emergency Care Unit for proper evaluation.

Recommendation strength: A.

Level of evidence: VI.

Recommendation 9

The presence of previous systemic diseases must always be investigated (see Recommendation n. 3).

\section{Clinical examination}

\section{Extra-oral examination}

a) Patient already examined by the Urgent Care Unit staff must be evaluated for:

- facial asymmetry

- pain
- reduced / altered temporo-mandibular joint (TMJ) mobility

- reduced / altered mandibular movements

- presence of ecchymosis, lacerations or abrasions of peri-oral soft tissues

b) Patient NOT examined by the Urgent Care Unit staff must be assessed for

- Clinical signs of head or cervical trauma

- Lesions such as ecchymosis, lesions due to recognizable objects, bite marks, etc. which may result from mistreatment or abuse

- Reduced mouth opening and deviation during mandibular movements pathognomonic of TMJ involvement (fractures, dislocations, endo-articular effusion)

- Pain (particularly when exacerbated by mandibular movements)

- Facial asymmetry

- Peri-oral soft tissues lesions such as lacerations or abrasions

\section{Intra-oral examination}

The dental assessment of traumatized patients, no matter if examined or not by the Urgent Care Unit staff, must always include evaluation of teeth and periodontal tissues conditions with special attention to:

- primary / mixed/ permanent dentition status

- teeth involvement and type of trauma (crown fractures, with or without pulp exposure, extrusive, intrusive or lateral dislocation and traumatic avulsion)

- occlusal post-traumatic alterations (open-bites, teeth with premature contacts)

- clinical examination of soft tissues to highlight alveolar bone exposure

- lesions involving oral mucosa, gums and tongue.

Recommendation 10

Careful clinical examination of the orofacial region must always be considered.

Recommendation strength: A.

Level of evidence: III.

Sub recommendation 10.1.

Any patient showing signs resulting from head/cervical trauma must be immediately sent to the Urgent Care Unit for proper evaluation.

Recommendation strength: A.

Level of evidence: IV. 
Sub recommendation 10.2.

If signs suggesting mistreatment/abuse are present in a patient who has NOT been examined at the Urgent Care Unit, the dental practitioner is required to report it to the competent authorities, as this is a legally punishable crime (see Mistreatment and child abuse chapter).

Recommendation strength: A.

Level of evidence: IV.

Recommendation 11

Palpate bone profiles of the face and evaluate any alterations of mandibular movements (reduced/ asymmetrical mouth opening) which may suggest TMJ involvement (fractures, dislocations, endo-articular effusion).

Recommendation strength: A.

Level of evidence: III.

Recommendation 12

Vitality test response (often unreliable in young children), percussion test and mobility of the involved teeth must always be considered (see "Guideline on Management of acute dental trauma of American Academy of Pediatric Dentistry Revised 2011").

Recommendation strength: A.

Level of evidence: I.

Recommendation 13

Dentinal/pulp exposure must be evaluated in case of spontaneous or stimulated local pain.

Recommendation strength: A.

Level of evidence: I.

\section{Radiological diagnostics}

A radiographic examination must be performed in every dental trauma. Intraoral radiography is useful to evidence root fracture, tooth displacement or avulsion. If lip wounds are present, radiological examination of soft tissues may be necessary to identify the presence of foreign bodies.

In case of fractures, orthopantomography, teleradiography in antero-posterior projection and/or advanced imaging methods must be considered. Inverse Towne's projection is recommended in very young and/or lowcompliant patients thanks to the low radiation dose delivered.

Recommendation 14

Periapical intraoral radiography is recommended in case of traumatized permanent teeth, traumatic avulsion of deciduous teeth or intrusive dislocation.

Recommendation strength: A.

Level of evidence: VI.

Sub recommendation 14.1.

In case of crown infraction of a permanent tooth, with no dental mobility, intraoral radiography can be postponed; tooth vitality and percussion test response should be monitored every 6 months.
Recommendation strength: B.

Level of evidence: VI.

\section{Certificate of the dental trauma}

Query: What criteria should be adopted by a dentist private practitioner to fill in a certificate in cases of dental or TMJ trauma occurring in growing subjects?

Keywords

Traumatic dental injuryDental traumaPediatric facial traumaMedico-legal issuesMedical certificateMedicolegal reportTMJ injury

Keywords have been searched alone and in association

Since the medico-legal reporting is regulated by national laws, The bibliographical search considered also national literature not included in the data banks described in the premise. A thorough evaluation of the selected study, no other studies emerged which were considered relevant for updating this chapter. Therefore the references' list considered here is the same as that of the previous edition of the document

Introduction

The certificate is an attestation released by a health professional upon the request of the entitled person for different reasons or interests, reporting facts or evidence found during clinical activity [74-77].

In case of orofacial trauma, the dentist must provide appropriate diagnostic and therapeutic assistance to patients, but could be also requested to fill in a certificate.

This certificate is a deontological duty for doctors and dentists [78] and for all other health professionals. The certificate must be appropriately filled in in terms of content and using the correct formal features as a report, otherwise some relevant hypothesis of penal, civil or deontological wrongdoing can be raised especially against dentists who practice as public officials (dentists employed in the National Health Service, e.g.)

Very few and simple rules are dictated for writing a certificate (see. Additional file 1), that is hard to be standardized in a sort of pre set up form, since the content of the certificate varies according to the different traumatic lesions and the scopes (that in any case should be legal and licit) that the patient or the entitled person (parents of a child, e.g.) intend to pursue [75-82]:

The filling in of the certificate should follow a few simple rules and avoids a "standard printed form "approach as the nature of dental or TMJ trauma can vary greatly and involves possible.

compensation claims by individuals and their parents.

The certificate requested for supporting a claim for compensation, should:

- Be filled in at the same time as the clinical examination is provided 
- Be clear and accurate in describing the trauma circumstances as reported by the patients, the clinical evidence, the diagnostic/therapeutic activity possibly performed and the prognosis. The certificate should detail if the patient need further exams or specialist referral (maxillo-facial surgeon, e.g.) for completing the diagnosis, specific treatments (provided by the dentist or other health professionals, such as a physiotherapist for TMJ trauma, e.g.), regular follow up with a possible reevaluation of the diagnosis, prognosis and the related treatments.

- Specify if a radiological or complementary examinations (pictures, dental casts, etc) should be integrated in the diagnostic activity

- Highlight if the reported evaluations (for future treatments and costs, e.g.) should be submitted to a medico-legal assessment [85]

For dental traumas occurring at school or during road accidents, the onus-of-the proof for the lesion entity and nature is on the injured person, consequently the dentist must appropriately document the traumatic lesions, before the therapeutic interventions (the extractions of a fractured tooth, e.g.) will render the lesion not verifiable by a subsequent assessor. This preliminary registration of clinical conditions must always be performed, apart from emergency cases in which the treatment cannot be safely delayed (tooth replantation, e.g.). [86].

Recommendation 1

The certificate released as an attestation of the nature and the entity of traumatic lesions must accurately report the anatomical site of the trauma, the diagnosis and the prognosis.

Recommendation strength: A.

Level of evidence: $\mathrm{V}$.

Recommendation 2 The traumatic lesion must be documented (patient file, X-rays, pictures, etc.) in an appropriate way by the dentist in order to provide objective clinical evidence that is useful from a medico-legal and judicial point of view for both penal or compensation purposes.

Recommendation strength: A.

Level of evidence: IV.

\section{Dental trauma as a result of neglect and or abuse of children}

Query: In the case of dental trauma, what are the elements that should lead clinicians to suspect nonaccidental trauma?

Keywords
Dental injuriesDental traumaPediatric facial traumaChild neglectChild abuseDomestic violenceChild mistreatment

The keywords were searched in association with each other.

Inclusion criteria: literature research also included national bibliographic sources, not reviewed by databases, in order to find national data on child abuse. We considered all studies that answered the above question for a total of 51 works. Five works, which included relevant results, were filed and added to the previous bibliography.

\section{Introduction}

In recent years there has been an increase in reports of minors in conditions of hardship and/or complaints against adults who are perpetrators of violence [83].

In some European countries and in the USA, there are specific surveillance registers, from which it is possible to obtain data on this phenomenon. It has been reported that about 3-6 children in 1000 suffer abuse of various types.

In Italy, the real extent of child abuse or neglect remains an underestimated problem [83] due to the lack of a national register and therefore, it is not possible to quantify the phenomenon with precise data. The prevalence rate estimated by the PES 2000 National Group is about 8 per thousand [84].

The World Health Organization underlines that "Child abuse or maltreatment constitutes all forms of physical and/or emotional ill-treatment, sexual abuse, neglect or negligent treatment or commercial or other exploitation, resulting in actual or potential harm to the child's health, survival, development or dignity in the context of a relationship of responsibility, trust or power [85].

In particular, there are four types of child maltreatment: physical abuse, sexual abuse, emotional abuse and neglect. Physical abuse occurs when the parents or guardians of the child practise or allow him/her to carry out acts, which may cause physical injury. The consequences of physical abuse are: injuries without lesions, skin and ocular lesions, visceral lesions, fractures, burns, multiple and repeated trauma [86].

Victims of child abuse can be found in all age groups, but the groups most at risk are new-born babies, infants and preschool children, particularly boys. The perpetrators are parents or caretakers in $90 \%$ of the cases, especially in young children [87].

Importantly, up to $50 \%$ of all physical injury associated with child abuse occurs in the head and neck region [88, 89]. A major study, performed on over 3385 subjects in developmental age with cranio-maxillo facial trauma, has shown that about $3.9 \%$ of cases was due to violence [90].

Regarding the trauma of the TMJ, some authors have shown that about $18 \%$ of the cases result from violence [91].

Fractures resulting from violence are most commonly associated with the angle region while those related to 
road traffic accidents usually involve the condyle, body and parasymphyseal fractures [92].

Regarding the face and neck, the oral cavity is less frequently affected by violence, but lesions at this level (bruising of the hard palate and springs, fractures tearing, burns of mucosae, etc.) can be easily detected by the health worker during an examination [93, 94].

Some authorities believe that the oral cavity may be a central focus for physical abuse because of its significance in communication and nutrition [95].

Generally, individuals subjected to abuse have lower levels of oral health $[96,97]$. Therefore, the role of the dental team in identifying possible signs of abuse is clear, because during an examination it is possible to see beyond the inside of the oral cavity, as well as checking the head, the face and the neck of traumatized patients being assessed after a traumatic event.

In general, characteristics of abuse injury are polymorphism, multiple locations and colours due to the repetition of the abuse in different ways and at different times $[98,99]$. A cohort study from Scotland reported that $59 \%$ of physically abused children had orofacial signs, such as bruises and abrasions that would be easily visible to a dentist. An apparent discrepancy in the trauma history provided by the parents and the injuries found on examination, or a delay in presentation along with a different history by each parent, should arouse suspicion in the clinician's mind regarding nonaccidental injury [48].

Although the oral cavity is a frequent site of sexual abuse in children, visible oral injuries or infections are rare. When oral-genital contact is suspected (in particular oral and perioral gonorrhea, or petechiae of the palate, particularly at the junction of the hard and soft palate) referral to specialized clinical settings equipped to conduct comprehensive examinations is recommended [95].

The presence of multiple lesions, dating back to different periods, in addition to specific injury (injuries caused by grabbing, fingernails, bites, cigarette burns etc.) should induce clinicians to take appropriate action in relation to the assistance profile (according to specific and appropriate specialized pathways) and in a timely manner and report the information to the relevant judicial authority. This is important not only to initiate judicial enquiries but also to put into place immediate procedures for the adoption of protection measures for the minor.

The evidence from the scientific literature revealed a discrepancy between the number of professionals who notice signs of violence against children and the number of professionals who report to the competent authorities. A study indicates that only $8 \%$ out of $28 \%$ of the dentists who noticed signs of violence against children reported this to the authorities [6].
An important problem is that, as various studies have shown, a significant number of dentists did not know which authorities to turn to in case of violence against children. Some authors observed that the dentists would contact the social and psychological services (21\%), lawyers $(10 \%)$, the police $(9 \%)$, as well as the District Attorney and the Children's Hospital (4\%) [6].

Health professionals, including dentists, are obliged by law to report suspicions of abuse when - in the exercise of their function - they suspect or are certain that a crime has been committed which can be officially prosecutable (art.331, 332 e 334 Code of Criminal Procedure, art. 361, 362 e 364 Criminal Code).

Finally, in Article 24 of the new Italian ELA (Essential Levels of Assistance) regarding "Social and health assistance to minors, to women, couples, families ", provision is made that, in the context of district, domiciliary and territorial assistance, the National Health Service guarantees to women, children, couples and families all services, including home care, medical, diagnostic and therapeutic assistance.

These services are necessary and appropriate in different areas of activities, which include: prevention, evaluation, assistance and psychological support for minors in situations of hardship, in state of neglect or victims of abuse as well as the psychological and social support to family units in conditions of hardship including evaluation and psychological support for couples and minors for family custody and adoption.

\section{Recommendation 1}

In the case of dental trauma, the health professional must always ask if such trauma may have been caused by abuse or violence and, in the event that it is suspected, must report it to the competent authorities.

Recommendation strength: A.

Level of evidence: IV.

Recommendation 2

In the presence of a dental injury, the clinicians must perform, in addition to a careful evaluation of the oral cavity, an examination of the head and neck.

Recommendation strength: A.

Level of evidence: IV.

Recommendation 3

It is important to carefully evaluate the trauma of the $\mathrm{TMJ}$ as sometimes it can be a result of violence or abuse.

Recommendation strength: A.

Level of evidence: IV.

Sub-recommendation

In particular, the intraoral examination must verify the presence of possible wounds to the lips, tongue, palate and frenula. Signs of previous dental traumas may be due to repeated trauma caused by violence. The extraoral examination must include the inspection of the scalp (verification of hair-free areas), of the auricles and of the 
neck (verification of the presence of wounds or bruises). Furthermore, it is important to evaluate the skin of the anatomical areas indicated above in order to verify the presence of abrasions, recent or old bruises and non-selfinflicted bite marks. The eyes should be inspected for the presence of periocular bruising and the nose for the detection of septal deviations or blood clots.

Recommendation strength: A.

Level of evidence: IV.

\section{Conclusions}

This document provides updated evidence-based guidance to assist dentists, paediatricians, surgeons, teachers, school and sport staff, parents in the prevention and first aid of dental trauma in children and adolescents and to provide a careful assessment of the medico-legal implications. Twenty-eight recommendations were given, divided in four domains. Regarding the first one "Dental trauma prevention strategies and health education", recommendations in home, school and sport environment are given. Particular importance is given to the organization of training courses for teachers, school employees and students with the aim to identify and reduce risks of dental trauma and to provide the correct firstaid. About "First aid in orofacial and dental trauma", recommendations are given regarding the immediate treatment of crown fracture and tooth avulsion and the general assessment of patient's condition after the trauma. Diagnostic procedures are also discussed. In the "Certificate of the dental trauma", it was assessed that the certification is a deontological duty for physicians and dentists and it needs to include a clear and accurate description of the trauma circumstances, clinical evidence, the diagnostic/therapeutic activity performed and the possible long-term prognosis. Few and simple rules helping to write a certificate are provided. Finally, in the "Dental trauma as a result of neglect and or abuse of children" section, it is highlighted that health professionals, including dentists, are obliged by law to report suspicions of abuse when, in the exercise of their function, they suspect or are certain that a crime has been committed which can be officially prosecutable.

\section{Supplementary information}

Supplementary information accompanies this paper at https://doi.org/10. 1186/s13052-019-0734-7.

Additional file 1:. Certificate form for orofacial trauma in children (DOCX $21 \mathrm{~kb}$ )

\section{Abbreviations}

AAPD: American Academy of Pediatric Dentistry; ANDI: (Associazione Nazionale Dentisti Italiani) Italian National Association of Dentists; APTRX: Postero-anterior cephalograms; ELA: Essential Levels of Assistance; GTO: (Gruppo tecnico sull'odontoiatria) "Technical Group for Dentistry"; IADT: International Association of Dental Traumatology; LL-TRX: Lateral cephalograms; OPG: Panoramic X-ray; PNLG: (Programma Nazionale per le Linee Guida) Italian National Guideline Programme; SIMEUP: (Società Italiana di Medicina di Emergenza ed Urgenza Pediatrica) Italian Society of Emergency Paediatricians; SITD: (Società Italiana di Traumatologia Dentale) Italian Dental Traumatology Society; TMJ: Temporomandibular joint; WHO: World Health Organization

\section{Acknowledgements}

The authors thank the Italian Ministry of health for supporting the panel's work.

\section{Authors' contributions}

The panel contributed equally to the bibliographic research, to the evaluation of the papers and to the drafting of the guideline. All authors read and approved the final Manuscript.

\section{Funding}

The authors did not receive any funding.

\section{Availability of data and materials}

Not applicable.

Ethics approval and consent to participate

Not applicable.

\section{Consent for publication}

Not applicable.

\section{Competing interests}

All the authors declared no competing interests.

\section{Author details}

${ }^{1}$ Department of Biomedical, Surgical and Dental Sciences, University of Milan, Via Beldiletto 1, Milan IT-20142, Italy. ${ }^{2}$ Italian Society of Dental Trauma (SITD), Via Pietro Marone 16, 25121 Brescia, Italy. ${ }^{3}$ Department of Neurosciences, University of Padova, Via Giustiniani 2, 35128 Padova, Italy. ${ }^{4}$ Department of Oral and Maxillo Facial Science, "Sapienza" University of Rome, Via Caserta 6, 00161 Rome, Italy. ${ }^{5}$ ASST Spedali Civili, Piazzale Spedali Civili 1, 25123 Brescia, Italy. ${ }^{6}$ Department of Surgical Sciences, University of Turin, Via Nizza 230, 10126 Turin, Italy. ${ }^{7}$ Department of Biomedical Sciences and Human Oncology, University of Bari, Piazza G. Cesare 11, 70124 Bari, Italy. ${ }^{8}$ Associazione Nazionale Dentisti Italiani, Lungotevere Raffaello Sanzio, 9, 00153 Rome, Italy. ${ }^{~}$ Unit 2, General Secretariat, Ministry of Health, Lungotevere Ripa, 1, 00153 Rome, Italy. ${ }^{10}$ Department of Neuroscience and Reproductive and Odontostomatological Sciences, "Federico II" University, Via Giosuè Carducci, 42 Naples, Italy. ${ }^{11}$ Department of Pediatric Dentistry, University of Brescia, P. le Spedali Civili 1, 25123 Brescia, Italy. ${ }^{12}$ Department of Health Sciences, University of Florence, Largo Brambilla, 3, 50134 Florence, Italy. ${ }^{13}$ Department of Medicine and Surgery, University of Parma, Via Gramsci 14, 43126 Parma, Italy. ${ }^{14}$ Department Oral and Maxillofacial Sciences, Sapienza University of Rome, Via Caserta 6, 00161 Rome, Italy. ${ }^{15}$ Health prevention, Italian Ministry of Health, Viale Giorgio Ribotta, 5 -, 00144 Rome, Italy. ${ }^{16}$ Department of Pediatrics, Pugliese-Ciaccio Hospital of Catanzaro, Viale Papa Pio X, 83, 88100 Catanzaro, Italy.

Received: 12 July 2019 Accepted: 14 October 2019

Published online: 04 December 2019

\section{References}

1. Emerich K, Wyszkowski J. Clinical practice: dental trauma. Eur J Pediatr. 2010; 169:1045-50.

2. Agrawal A, Kumar $P$, Singhal $R$, Singh $V$, Bhagol A. Animal bite injuries in children: review of literature and case series. Int J Clin Pediatr Dent. 2017;10: $67-72$.

3. Sigurdsson A. Evidence-based review of prevention of dental injuries. Pediatr Dent. 2013;35:184-9.

4. Borges TS, Vargas-Ferreira F, Kramer PF, Feldens CA. Impact of traumatic dental injuries on oral health-related quality of life of preschool children: a systematic review and meta-analysis. PLoS One. 2017;12:e0172235.

5. American Academy of Pediatrics Committee on Child Abuse and Neglect and the American Academy of Pediatric Dentistry Council on Clinical Affairs. 
Guideline on Oral and Dental Aspects of Child Abuse and Neglect. Pediatr Dent. 2016;38:73-6.

6. Rodrigues JLSA, Lima APB, Nagata JY, Rigo L, Cericato GO, Franco A, Paranhos LR. Domestic violence against children detected and managed in the routine of dentistry - a systematic review. J Forensic Legal Med. 2016;43:34e41.

7. Malaga EG, Aguilera EM, Eaton C, Ameerally P. Management of Self-Harm Injuries in the Maxillofacial Region: A Report of 2 Cases and Review of the Literature. J Oral Maxillofac Surg. 2016;74(1198):e1-9.

8. Holan G, Shmueli Y. Knowledge of physicians in hospital emergency rooms in Israel on their role in cases of avulsion of permanent incisors. Int J Paediatr Dent. 2003;13:13-9.

9. Istituto Superiore di Sanita. Manuale metodologico - Come produrre, diffondere e aggiornare raccomandazioni per la pratica clinica - May 2002.

10. Lam R. Epidemiology and outcomes of traumatic dental injuries: a review of the literature 2016. Aust Dent J. 2016;61:4-20.

11. Faus-Damia M, Alegre-Domingo T, Faus-Matoses I, Faus-Matoses V. FausLlacer VJ. Traumatic dental injuries among schoolchildren in Valencia, Spain. Medicina Oral. Patologia Oral Cir Bucal. 2011;16:e292-5.

12. Hegde AM, Pradeep Kumar KN, Varghese E. Knowledge of dental trauma among mothers in Mangalore. Dent Traumatol. 2010;26:417-21.

13. Chan YM, Williams S, Davidson LE, Drummond BK. Orofacial and dental trauma of young children in Dunedin. New Zealand Dent Traumatol. 2011; 27:199-202.

14. Al-Obaida M. Knowledge and management of traumatic dental injuries in a group of Saudi primary schools teachers. Dent Traumatol. 2010;26:338-41.

15. Andrade RA, Evans PL, Almeida AL, da Silva JJ, Guedes AM, Guedes FR, Ranalli DN, Modesto A, Tinoco EM. Prevalence of dental trauma in Pan American games athletes. Dent Traumatol. 2010;26:248-53.

16. Levin L, Zadik Y. Education on and prevention of dental trauma: it's time to act! Dent Traumatol. 2012;28:49-54.

17. Istat Report 2014 - Gli incidenti domestici. Pubblicato 1 aprile 2016. (https:// www.istat.it/it/archivio/183893, accessed October 2017).

18. Noori AJ, Al-Obaidi WA. Traumatic dental injuries among primary school children in Sulaimani city. Iraq Dent Traumatol. 2009;25:442-6.

19. Glendor U. Aetiology and risk factors related to traumatic dental injuries - a review of the literature. Dent Traumatol. 2009;25:19-31.

20. Goettems ML, Schuch HS, Hallal PC, Torriani DD, Demarco FF. Nutritional status and physical activity level as risk factor for traumatic dental injuries occurrence: a systematic review. Dent Traumatol. 2014;30:251-8.

21. Kramer PF, Feldens EG, Bruch CM, Ferreira SH, Feldens CA. Clarifying the effect of behavioral and clinical factors on traumatic dental injuries in childhood: a hierarchical approach. Dent Traumatol. 2015;31:177-83.

22. Siqueira MB, Gomes MC, Oliveira AC, Martins CC, Granville-Garcia AF, Paiva SM. Predisposing factors for traumatic dental injury in primary teeth and seeking of post-trauma care. Braz Dent J. 2013;24:647-54.

23. Gupta S, Kumar-Jindal S, Bansal M, Singla A. Prevalence of traumatic dental injuries and role of incisal overjet and inadequate lip coverage as risk factors among 4-15 years old government school children in BaddiBarotiwala area, Himachal Pradesh, India. Med Oral Patol Oral Cir Bucal. 2011;16:960-5.

24. Borzabadi-Farahani A. The association between orthodontic treatment need and maxillary incisor trauma, a retrospective clinical study. Oral Surg Oral Med Oral Pathol Oral Radiol Endod. 2011;112:75-80.

25. Chhabra S, Chhabra N, Gaba S. Maxillofacial injuries due to animal bites. J Maxillofac Oral Surg. 2015;14:142-53.

26. Stefanopoulos PK, Tarantzopoulou AD. Management of facial bite wounds. Dent Clin N Am. 2009;53:691-705.

27. Wasserman GS, Lowry J, Algren DA. Bites. In: Holcomb GW, Murphy JP, editors. Ashcraft's pediatric surgery. 5th ed. Philadelphia: Saunders/Elsevier; 2009. p. 144-53.

28. Arikan V, Sönmez H. Knowledge level of primary school teachers regarding traumatic dental injuries and their emergency management before and after receiving an informative leaflet. Dent Traumatol. 2012;28:101-7.

29. Ramroop V, Wright D, Naidu R. Dental health knowledge and attitudes of primary school teachers toward developing dental health education. West Indian Med J. 2011;60:576-80.

30. Soubra BN, Debs NN. Impact of audiovisual method in educating children facing dental avulsion. Dent Traumatol. 2014;30:216-21.

31. Müller KE, Persic R, Pohl Y, Krastl G, Filippi A. Dental injuries in mountain biking - a survey in Switzerland, Austria. Germany and Italy Dent Traumatol. 2008;24:522-7.
32. Sepet E, Aren G, Dogan Onur O, Pinar Erdem A, Kuru S, Tolgay CG, Unal S. Knowledge of sports participants about dental emergency procedures and the use of mouthguards. Dent Traumatol. 2014;30:391-5.

33. Caglar E, Kuscu OO, Caliskan S, Sandalli N. Orofacial and dental injuries of snowboarders in Turkey. Dent Traumatol. 2010;26:164-7.

34. Çetinbas T, Yildirim G, Sönmez $H$. The relationship between sports activities and permanent incisor crown fractures in a group of school children aged 7-9 and 11-13 in Ankara. Turkey Dent Traumatol. 2008;24:532-6.

35. Amadori F, Bardellini E, Copeta A, Conti G, Villa V, Majorana A. Dental trauma and bicycle safety: a report in Italian children and adolescents. Acta Odontol Scand. 2017;75:227-31.

36. Diangelis AJ, Andreasen JO, Ebeleseder KA, Kenny DJ, Trope M, Sigurdsson A, et al. International Association of Dental Traumatology guidelines for the management of traumatic dental injuries: 1. Fractures and luxations of permanent teeth. Dent Traumatol. 2012;28:2-12.

37. Andreasen JO, Lauridsen E, Gerds TA, Ahrensburg SS. Dental trauma guide: a source of evidence - based treatment guidelines for dental trauma. Dent Traumatol. 2012;28:345-50.

38. Hasan AA, Qudeimat MA, Andersson L. Prevalence of traumatic dental injuries in preschool children in Kuwait - a screening study. Dent Traumatol. 2010;26:346-50.

39. Rohini D, Sharma S. Prevalence, causes, and correlates of traumatic dental injuries among seven-to-twelve-year-old school children in Dera Bassi. Contemp Clin Dent. 2012;3:38-41.

40. Blokland A, Watt RG, Tsakos G, Heilmann A. Traumatic dental injuries and socioeconomic position - findings from the Children's dental health survey 2013. Community Dent Oral Epidemiol. 2016;44:586-91.

41. Andersson L. IADT guidelines for the management of traumatic dental injures: 2. Avulsion of permanent teeth. Dent Traumatol. 2012;28:88-96.

42. Brüllmann D, Schulze RK, d'Hoedt B. The treatment of anterior dental trauma. Dtsch Arztebl Int. 2010;108:565-70.

43. Govindarajan M, Reddy VN, Ramalingam K, Durai KS, Rao PA, Prabhu A. Prevalence of traumatic dental injuries to the anterior teeth among three to thirteen-year-old school children of Tamilnadu. Contemp Clin Dent. 2012;3: 164-7.

44. Emerich $\mathrm{K}$, Gazda E. Review of recommendations for the management of dental trauma presented in first-aid textbooks and manuals. Dent Traumatol. 2010;26:212-6.

45. Baginska J, Wilczynska-Borawska M. First-aid algorithms in dental avulsion. J Sch Nurs. 2012;28:90-4.

46. American Academy of Pediatric Dentistry (AAPD). Guidelines on Management of Acute Dental Trauma. Chicago, IL: American Academy of Pediatric Dentistry; 2011.

47. Malmgren B, Andreasen JO, Flores MT, Robertson A, DiAngelis AJ, Andersson $L$, et al. IADT guidelines for the management of traumatic dental injures: 3. Injuries in the primary dentition. Dent Traumatol. 2012;28:174-82.

48. Ranka M, Dhaliwal H, Albadri S, Brown C. Trauma to the primary dentition and its Sequelae. Dent Update. 2013;40:534-42.

49. Vazquez MP, Kadlub N, Soupre V, Galliani E, Neiva-Vaz C, Pavlov I, et al. Facial trauma and injury in children. Ann Chir Plast Esthet. 2016;61:543-59.

50. Meiera JD, Tollefsonb TT. Pediatric facial trauma. Curr Opin Otolaryngol Head Neck Surg. 2008;16:1-7.

51. Steelman R. Rapid physical assessment of the injured child. J Endod. 2013; 39:S9-12.

52. Eggensperger Wymann NM, Hölzle A, Zachariou Z, lizuka T. Pediatric Craniofacial Trauma. J Oral Maxillofac Surg. 2008;66:58-64.

53. Hu CF, Fan HC, Chang CF, Chen SJ. Current approaches to the treatment of head injury in children. Pediatr Neonatol. 2013;54:73-81.

54. Berg MD, Schexnayder SM, Chameides L, Terry M, Donoghue A, Hickey RW, et al. Pediatric basic life support: 2010 American Heart Association guidelines for cardiopulmonary resuscitation and emergency cardiovascular care. Circulation. 2010;122:5862-75.

55. Kleinman ME, Chameides L, Schexnayder SM, Samson RA, Hazinski MF, Atkins DL, et al. Pediatric advanced life support: 2010 American Heart Association guidelines for cardiopulmonary resuscitation and emergency cardiovascular care. Pediatrics. 2010;126:e1361-99.

56. Kleinman ME, de Caen AR, Chameides L, Atkins DL, Berg RA, Berg MD, et al. Pediatric basic and advanced life support chapter collaborators. Pediatric basic and advanced life support: 2010 international consensus on cardiopulmonary resuscitation and emergency cardiovascular care science with treatment recommendations. Circulation. 2010;122:5466-515. 
57. Kambalimath HV, Agarwal SM, Kambalimath DH, Singh M, Jain N, Michael P. Maxillofacial injuries in children: a 10 year retrospective study. J Maxillofac Oral Surg. 2013;12:140-4.

58. John B, John RR, Stalin A, Elango I. Management of mandibular body fractures in pediatric patients: a case report with review of literature. Contemp Clin Dent. 2010;1:291-6.

59. Sharma S, Vashistha A, Chugh A, Kumar D, Bihani U, Trehan M. Nigam AG pediatric mandibular fractures: a review. Int J Clin Pediatr Dent. 2009;2:1-5.

60. Pirttiniemi $P$, Peltomäki T, Müller $L$, Luder HU. Abnormal mandibular growth and the condylar cartilage. Eur J Orthod. 2009;31:1-11.

61. Aldrigui JM, Abanto J, Carvalho TS, Mendes FM, Wanderley MT, Bönecker M, et al. Impact of traumatic dental injuries and malocclusions on quality of life of young children. Health Qual Life Outcomes. 2011;9:78

62. Cyrus DM, Kelvin Al, Marleau A. How do I manage a patient with lateral luxation of a permanent incisor? J Can Dent Assoc. 2016:82g21.

63. Holan G. Replantation of avulsed primary incisors: a critical review of a controversial treatment. Dent Traumatol. 2013;29:178-84.

64. Gungor HC. Management of crown-related fractures in children: an update review. Dent Traumatol. 2014;30:88-99.

65. Fariniuk LF, De Sousa MH, Westphalen VP, Carneiro E, Silva Neto UX, Roskamp $L$, et al. Evaluation of care of dentoalveolar trauma. J Appl Oral Sci. 2010;18:343-5

66. Owtad P, Park JH, Still AT, Shastry S. Management guidelines for traumatically injured teeth during orthodontic treatment. J Clin Paediatr Dent. 2015;39:292-6.

67. Srivastava A, Gupta N, Marleau A, Afrashtehfar Kl. How do I manage a patient with intrusion of a permanent incisor? J Can Dent Assoc. 2014;80:1-6.

68. Guedes $\mathrm{OA}$, de Alencar AH, Lopes LG, Pécora JD, Estrela C. A retrospective study of traumatic dental injuries in a Brazilian dental urgency service. Braz Dent J. 2010;21:153-7.

69. Naeem A, Gemal H, Reed D. Imaging in traumatic mandibular fractures. Quant Imaging Med Surg. 2017;7:469-79.

70. Ogura I, Sasaki Y, Kaneda T. Analysis of mandibular condylar and glenoid fossa fractures with computed tomography. Eur Radiol. 2014;24:902-6.

71. May JJ, Cohenca N, Peters OA. Contemporary Management of Horizontal Root Fractures to the permanent dentition: diagnosis-radiologic assessment to include cone-beam computed tomography. Pediatr Dent. 2013;35:120-4

72. Glendor U. Has the education of professional caregivers and lay people in dental trauma care failed? Dent Traumatol. 2009:25:12-8.

73. Pithon MM. Lacerda dos Santos R, Magalhães PH, Coqueiro Rda S. Brazilian primary school teachers' knowledge about immediate management of dental trauma. Dental Press J Orthod. 2014;19:110-5.

74. Razik H, Benyaich H, Aghjdam I, Louahlia S. Medico-legal certificates in dentistry-oral medicine. Odontostomatol Trop. 2003;26:14-8.

75. Turillazzi E. Deontologia medica, in Norelli G, Buccelli C, Fineschi V, Medicina legale e delle assicurazioni. Padova: Piccin; 2009.

76. Mazzucchelli L, Scarpelli M. I traumi dentali: aspetti clinici e medico-legali, Ed. Milano: Sinergie; 2007.

77. Millet J. Analysis of medical certificate dealing with dental lesions. J Med Legale Droit Medicale. 2000;43:211-3.

78. Codice di deontologia medica; articolo 24 "certificazione", 2006. http:// portale.fnomceo.it.

79. Baima Bollone P. Certificati, consulenze e perizie. In: Baima Bollone P, Legale M, Torino GE, editors. I trattamenti sanitari obbligatori; 2002.

80. Bonelli A, Mazzeo E. II certificato, in Norelli GA. Piccin, Padova: Pinchi V. Ontologia Forense parte I; 2011

81. De Salvia A, Sergolini L, Pescarolo D. An atypical air bag injury? J Forensic Odontostomatol. 2007;25:57-60.

82. Marić M, Leone F, Danesino P. Medico-legal considerations in orthodontic traumatology. Mondo Ortodontico. 2010;35:26-35.

83. Di Blasio P, Rossi G. Trascuratezza, maltrattamento e abuso in danno dell'infanzia: Servizi e Centri presenti in Regione Lombardia Centro di Ricerca delle Tecnologie dell'Istruzione (C.R.T.I.) Famiglia e Solidarietà Sociale, Centro Studi e Documentazione sui Servizi alla Persona G.M. Cornaggia Medici Gennaio 2004

84. Gruppo Nazionale PES 2000. Prevalenza, caratteristiche e fattori di rischio ne maltrattamento infantile: una overview dei risultati di uno studio nazionale in 19 servizi di Pronto Soccorso Pediatrico. Gruppo Nazionale PES-2000 pp 200-206 in Istituto Superiore di Sanità, Progetto Nazionale Salute Mentale. Rapporti ISTISAN 01/27.
85. Krug EG, Dahlberg L, Mercy JA, Zw AB, Lozano R. Word report on violence and health. Geneva: World Health Organization; 2002. http:// whqlibdoc. who.int/hq/2002/9241545615.pdf

86. Bianchi D, Moretti E. Quaderni del Centro nazionale di documentazione e analisi per l'infanzia e l'adolescenza. In: Vite in bilico. Indagine retrospettiva su maltrattamenti e abusi in età infantile. Firenze: Istituto degli Innocenti, ottobre; 2006. Available at www.minori.it/quaderno-40.

87. Zimmermann CE, Troulis MJ, Kaban LB. Pediatric facial fractures: recent advances in prevention, diagnosis and management. Int J Oral Maxillofac Surg. 2006;35:2-13.

88. Donaruma-Kwoh MM, Wai S. Oropharyngeal lesions and trauma in children. Clin Pediatr Emerg Med. 2010;11:112-21.

89. Costello BJ, Papadopoulos H, Ruiz R. Pediatric Craniomaxillofacial Trauma. Clin Pediatr Emerg Med. 2005;6:32-40.

90. Gassner R, Tuli T, Hä chl O, Moreira R, Ulmer H. Craniomaxillofacial trauma in children: a review of 3,385 cases with 6,060 injuries in 10 years. J Oral Maxillofac Surg 2004;62:399-407.

91. Monnazzi MS, Gabrielli MAC, Gabrielli MFR, Trivellato E. Treatment of mandibular condyle fractures. A 20-year review. Dent Traumatol. 2017;33:175-80.

92. Nasser M, Pandis N, Fleming PS, Fedorowicz Z, Ellis E, Ali K. Interventions for the management of mandibular fractures. Cochrane Database Syst Rev. 2013:7:CD006087.

93. McAndrew M, Marin MZ. Role of dental professional identification and referral of victims of domestic violence. N Y State Dent J. 2012;78:16-20.

94. Nelms AP, Gutmann ME, Solomon ES, DeWald JP, Campbell PR. What victims of domestic violence need from the dental profession. J Dent Educ. 2009;73:490-8

95. American Academy of Pediatrics Committee on Child Abuse and Neglect; American Academy of Pediatric Dentistry;. 2008-2009;30:86-9.

96. Montecchi PP, Di Trani M, Sarzi Amadè D, Bufacchi C, Montecchi F, Polimeni A. The dentist's role in recognizing childhood abuses: study on the dental health of children victims of abuse and witnesses to violence. Eur J Paediatr Dent. 2009:10:185-7.

97. Polimeni A. Odontoiatria pediatrica. Milano: Elsevier Masson Italia; 2012.

98. Cingolani M, Benedetto G, Fornaio A, Rodriguez D. La tutela dei minori dai maltrattamenti: il ruolo dell'odontoiatra. Riv Ital Med Leg. 2001;23:691-711.

99. Sujatha G, Sivakumar G. And TR Saraswathi. Role of a dentist in discrimination of abuse from accident. J Forensic Dent Sci. 2010;2:2-4.

\section{Publisher's Note}

Springer Nature remains neutral with regard to jurisdictional claims in published maps and institutional affiliations.

Ready to submit your research? Choose BMC and benefit from:

- fast, convenient online submission

- thorough peer review by experienced researchers in your field

- rapid publication on acceptance

- support for research data, including large and complex data types

- gold Open Access which fosters wider collaboration and increased citations

- maximum visibility for your research: over $100 \mathrm{M}$ website views per year

At $\mathrm{BMC}$, research is always in progress.

Learn more biomedcentral.com/submissions 